\title{
Sociology
}

\section{Falling back into Gender? Men's Narratives and Practices around First-time} Fatherhood

Tina Miller

Sociology published online 19 November 2011

DOI: $10.1177 / 0038038511419180$

The online version of this article can be found at:

http://soc.sagepub.com/content/early/2011/11/18/0038038511419180

\section{Published by:}

(\$)SAGE

http://www.sagepublications.com

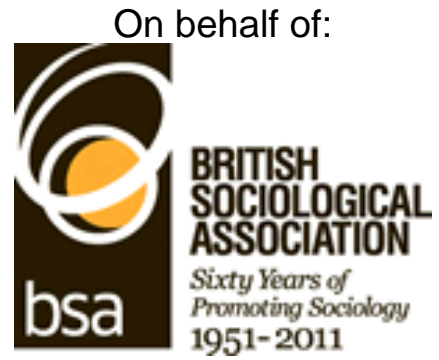

British Sociological Association

Additional services and information for Sociology can be found at:

Email Alerts: http://soc.sagepub.com/cgi/alerts

Subscriptions: http://soc.sagepub.com/subscriptions

Reprints: http://www.sagepub.com/journalsReprints.nav

Permissions: http://www.sagepub.com/journalsPermissions.nav

$$
\text { >> Proof - Nov 19, } 2011
$$

What is This? 


\title{
Falling back into Gender? Men's Narratives and Practices around First-time Fatherhood
}

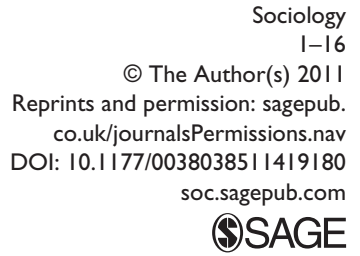

\section{Tina Miller}

Oxford Brookes University, UK

\begin{abstract}
This article explores men's articulations and practices of gender through transition to first-time fatherhood. Using qualitative longitudinal data, men's antenatal intentions and postnatal practices are explored in this study which replicates earlier research on motherhood. The contemporary context in the UK is one where paternity leave, discourses of caring masculinities and more public displays of fathering involvement appear to offer new possibilities for men. But data analysis shows that whilst opportunities to disrupt gender norms are initially imagined, longer term practices can confirm 'patriarchal habits'. The findings illuminate gender being done and undone, at times simultaneously, as the exhaustion and hard work of new parenting is encountered. A retreat into normative behaviours can be a path of least resistance as experiences unfold in an arena where men are found to have available to them a wider repertoire of discursive storylines. Optimistically, some changes in fathering involvement are discernible.
\end{abstract}

\section{Keywords}

caring practices, fatherhood, men, paid work, qualitative longitudinal research

\section{Background}

A recurrent theme across scholarship on gender, equality and family lives is that new questions need to be asked or old ones reframed. This is as a consequence of the 'stalled' and 'slow processes of change' that continue to pattern the organization of paid work, domestic tasks and caring for children, discernible in gendered and unequal ways across western societies (Björnberg and Kollind, 2005: 139; Coltrane, 1996; Thébaud, 2010; Townsend, 2002). More particularly, in order to better understand how men as fathers

\footnotetext{
Corresponding author:

Tina Miller, Oxford Brookes University, Gipsy Lane Campus, Oxford OX3 OBP, UK.

Email: tamiller@brookes.ac.uk
} 
occupy these spaces, the need to 'open a conversation' and 'talk about fathers differently' has been urged (Ruddick, 1997: 217). Similarly, the need to take account of 'how and under what circumstances women and men reproduce, break or transgress gender norms' around the division of labour and family life has also been noted (Björnberg and Kollind, 2005: 126). These various calls are informed by, and emanate from, theoretical debates around 'doing' and 'undoing gender' and how these are practised in everyday life (West and Zimmerman, 1987). The need to focus in more precise ways on daily practices, which either reproduce or reduce and so could be claimed to undo or dismantle gender differences, has become a more recent concern (Deutsch, 2007: 107; Risman, 2009). So too has the need to more critically engage with 'issues of conflict, power and control' in social relations so as to move beyond explanations of doing and undoing gender only at the level of individual practices of agency (Fox, 2009: 32-3). Drawing on these calls for an analytic shift in explorations of gender, family contexts and individual practices, this article examines the 'micro politics' of men's intentions and practices of anticipating and then doing early fathering, set against a slowly shifting societal landscape (Hearn and Pringle, 2006).

The data in this article are taken from a qualitative longitudinal study on transition to first-time fatherhood in the UK carried out between 2005 and 2009. Using interview schedules similar to those used in an earlier study on transition to motherhood (Miller, $2005,2007)$, this study explores how a group of men make sense of their transition through a focus on the strands of discourse they draw on in narrating transition experiences. This longitudinal focus and juxtaposing of rich, qualitative data illuminates the dynamic relationship between intention, experience, masculine choices and everyday practices. It enables glimpses of new possibilities to be discerned (undoing gender?) in the early weeks following the birth as men become involved in caring practices, but all too soon circumstances can lead the new fathers (and so the new mothers) to fall back into normative gendered behaviours. The unfolding data illuminate how a more precise focus on behaviours which constitute doing and undoing gender, over time, can reveal men's simultaneous engagement in such practices and also how masculine choices are constructed in this historically maternal arena. Although the obduracy of 'patriarchal habits' (Ruddick, 1997: 213) remains in evidence, so too are new possibilities gleaned across the men's unfolding narratives.

The need for a 'renewed analysis of agency' and 'intent' in relation to how gender is done or undone and so theorized requires that attention be paid to the contexts in which practices of agency unfold (Jurik and Siemsen, 2009: 73). The context here involves changing structural features (e.g. women's participation in paid work and the feminization of work, together with the introduction of paternity leave); more nuanced understandings of masculinities and associated discursive opportunities; and the continued findings in feminist scholarship of the erroneous conflation of women and essentialist caring capacities. These overlapping occurrences provide a backdrop which appears to make possible thinking and acting differently about how caring for children is organized and practised - how gender is done and/or undone in this arena. Each of these areas will be considered further below. Individual experiences of fatherhood are of course multiple and varied but ideals of 'involved fatherhood' are more narrowly drawn in many western societies: although not nearly as narrowly drawn as those which circumscribe 
motherhood (Dermott, 2008; Doucet, 2006; Miller, 2007; Wall and Arnold, 2007). Men becoming fathers largely escape the 'totalizing effects' of the 'official' and 'unofficial' discourses which frame motherhood and emphasize women's biological capacities and their need for medical expertise (Duden, 1993).

The discourses which frame men's experiences of transition to fatherhood do not invoke biological predisposition or the need for medical surveillance. Rather, they are rooted in powerful social, cultural and historical constructions of hegemonic masculinities (the breadwinner as economic provider and protector), as well as more recent constructions of 'involved fatherhood' and the 'good father' (Connell, 1995; Wall and Arnold, 2007). This latter construction emerges as a consequence of the greater recognition of masculinity as plural and diverse and able to incorporate notions of 'caring masculinities', 'intimacy' and emotional displays together with some notion of gender equality (Dermott, 2008; Johansson and Klinth, 2007). Further framing of contemporary fatherhood is also provided through policy discourses which can invoke equality and rights, and position fathers as 'problems' who require legislative measures in order to ensure family 'responsibilities' (usually financial) are met. The absent and non-providing 'bad father' is also a recognizable figure within UK policy and wider public discourse. Societal visions and cultural representations of how things should be are then produced and reinforced through discourses which, in this context, inflect contemporary ideas and gendered and classed constructions of what (good) fathering should be (Gillies, 2009; Knijn and Selten, 2002; O'Brien, 2005). Although discourses provide important societal frameworks, they are always suffused with, and reinforce, gendered expectations and behaviours. Gender, then is 'always lurking in the background ... across different situations' (Deutsch, 2007: 116), but around motherhood and fatherhood gender usually sits centre stage.

Contemporary western representations of involved fatherhood emphasize greater emotional closeness in men's 'relationships with their children' and men's sharing of 'the joys and work of caregiving with mothers' (Wall and Arnold, 2007: 509). But at the outset it is important to note the gendered and patriarchal struggles which have implicitly and explicitly configured women's 'historical connection to care giving' and men's absence from it (Doucet, 2006: 29). Clearly, this is not uncontested terrain. Choices and constraints in relation to practices of agency across caring and paid work are etched through with historical precedent and behaviours which have been shaped in relation to patriarchy (Ruddick, 1997). In stark contrast to constructions of motherhood and women's lives, where much has been simplistically universalized and taken for granted, the relationship between men and fatherhood is much less clear. It is little surprise then that even where discourses of equality and policies to facilitate shared caring exist (e.g. in Nordic countries), men are still more able to determine "the terms for their engagement and participation' and caring continues to be more generally viewed as a female practice: but change and even 'dissolution' of these arrangements are discernible too (Björnberg and Kollind, 2005: 128).

The shifting structural context invoked above refers in the UK to the introduction in 2003 of two weeks' paid paternity leave and the right for fathers to request 'flexible working'. UK employers now have a 'duty' to consider parental leave requests and further consultation on the division of parental leave is currently underway. ${ }^{1}$ Whilst the UK is many years behind other northern European countries in relation to policies focusing 
on gender equality in family life (e.g. Sweden), it is ahead of other industrialized countries (e.g. Ireland and the USA), where economic fatherhood - 'breadwinning' - continues to be more singularly emphasized (Townsend, 2002: 157). These policy changes across Europe (coined the 'Nordic turn') have coincided with and/or prompted other shifts which make more emotionally involved, hands-on fathering seem both possible and plausible (Wall and Arnold, 2007: 509). For example, understandings of masculinity as multiple and fluid and visions 'of a new care-oriented masculinity' and the 'nurturing man' are discernible in promotions of father involvement in caring (Johansson and Klinth, 2007: 2; Vuori, 2007). Related discourses have also provided (some) men with the 'discursive resources' to articulate new demands in both public and private spheres (Hobson and Morgan, 2002: 14). Nevertheless, it is important to note the diversity which patterns men's lives as fathers and family variability, and to note that just because policies which can facilitate fathering involvement exist does not ensure their take up (Deutsch, 2007: Duncan et al., 2010; Featherstone, 2009; Henwood and Proctor, 2003; Lupton and Barclay, 1997).

Changes in men's lives as fathers clearly have implications for women's lives too. Mothering and fathering are supremely gendered, contingent practices in which parents can 'struggle against their own patriarchal habits' (Ruddick, 1997: 213). Ambiguity and ambivalence also inflect understandings and experiences of maternal - and paternal subjectivities and agency: so too essentialist discourses which can be drawn upon in sometimes perturbing ways to underscore and reinforce gendered positions and/or inhibit change. Research over many years has also concluded that men have greater powers to choose the parameters of their involvement in family life (Gatrell, 2007; Lamb et al., 1987; Townsend, 2002). Yet others have more recently claimed that involvement in fatherhood is more a consequence of structural circumstances that are not of men's choosing (Featherstone, 2009; Williams, 2008). These apparently competing positions on masculine practices of agency and power underpin fathering involvement and in practice both positions are tenable: that men do have more power than women in many areas that shape family lives, and that these have become embedded and durable, within contexts and discourses which for contemporary fathers may not be of their choosing (McNay, 2000; Marsiglio and Pleck, 2005). Moving to a context in which 'creating equality in everyday life' becomes a possibility is then largely about 'doing gender' differently according to Björnberg and Kollind (2005: 131), or conversely can be indicative of 'undoing gender' using Deutsch's definition of behaviours that reduce gender inequality with the potential to become 'genderless' (2007: 122).

In this article I focus on the experiences of men who appear to conform to normative visions and associated discourses of those who constitute the good 'involved' father. They are employed in skilled jobs that mostly position them as middle class and appear to afford them some job security. They are partnered (some are married) and they are becoming fathers at a culturally appropriate stage in an adult life-course and are the biological father of their (unborn) child(ren). They are white (several are in ethnically mixed partnerships or marriages) and heterosexual. The pregnancies are mostly planned and the men are eligible for statutory paternity leave and some talk of the possibility of 'flexible working' and 'family-friendly work place policies'. Indeed, the men could be described as living and working in circumstances which more readily facilitate father 
involvement and opportunities to disrupt traditional normative behaviours around caring and paid work. But what can and do their accounts of intentions and subsequent practices of first-time fathering enable us to say about individual, masculinist practices of agency, caring and theorizations of doing and undoing gender?

\section{The Study}

The data drawn upon in this article were generated from a UK study that focused on a group of men and their experiences of transition to first-time fatherhood. The study repeated an earlier study on transition to first-time motherhood (Miller, 2005, 2007). ${ }^{2}$ In the current study, 17 men were interviewed across approximately two years in their lives in which they became fathers. The iterative research process involved interviewing the men on up to four separate occasions, followed by an end-of-study postal questionnaire used to collect data on their experiences of participating in the study. Semi-structured interview schedules used in the earlier motherhood study were adapted and used in the interviews. The schedules covered areas around expectations, birth, fathering experiences, perceptions of self, caring, work intentions and practices. The first interview took place antenatally at between seven to eight months, once the pregnancy was well established. The second interview took place between six and 12 weeks postnatally. The third interview took place between nine and 12 months postnatally and an additional, fourth interview with nine of the fathers took place at around the time of their child's second birthday. In the first interview participants were asked to describe how they had felt when they found out they were to become a father. Subsequently, interviews began with a question asking participants to describe what had happened since the last interview. This approach gave the men the opportunity to narrate their accounts of anticipating and later experiencing fathering and fatherhood in the ways they wished and felt comfortable. In contrast to the earlier motherhood study, and echoing the ethical regulation of research now more prevalent across institutions and organizations, I was required to get university ethics approval for this study. A consequence of this was that potential participants were required to 'opt in' to the research and to provide written consent. In spite of using a diverse range of work places, shops, leisure and other premises to advertise the research, the eventual sample of 17 men who participated in this longitudinal study were all white, employed, heterosexual and living in dual-earner households. The mean age of the participants was 33.7 years at the time of the first interview; ages ranged from 24 years to 39 years. In the UK, average paternal age is on the increase and the mean age of fathers in England and Wales had increased to 32.1 years in 2003 (Bray et al., 2006).

Most of the interviews were carried out in the participant's home. Following the first interview, I began subsequent interviews by reminding participants of what had been said in the previous interview using their words ('when we last met you said ... '). This approach also allowed me to explore developing concepts. The longitudinal design of the research helped to capture unfolding experiences of transition which could not be achieved through one-off interviews (Shirani and Henwood, 2011). Indeed, had the study terminated after the first interview the data would have indicated that 'new man' had been found and that gender equality was alive and well and patterning lives and 
parenting choices at the everyday level. In the event this turned out not to be the case and the longitudinal data revealed a more complex picture in which attitudes were found to be changing more rapidly than actual practices. In practice, opportunities to be involved and sharing caring 'equally' are not (fully) realized between exhausted new parents who mostly just want to get through ('survive') these early weeks (Fox, 2009). All interviews were recorded with the participants' permission and at the end of the study transcripts of the interviews were sent to those who wanted them as a token of thanks rather than for data checking purposes. The 57 interviews, which lasted between one and three hours, were transcribed verbatim. Analysis of the data was initially individual, thematic and temporal, involving examining how and when the men drew on different discourses to narrate their initial intentions and later practices of caring and paid work. These individual stories were then compared and patterns identified across the whole data set. The analysis revealed that men have available to them a wider range of possible 'storylines' when compared to women becoming mothers (Miller, 2011). A wider array of discourses could be drawn upon to initially imagine and narrate involved fathering, then to make sense of the intense post-birth period, and finally to justify how earlier imaginings of equal, shared involvement and 'sameness' in caring practices could not be fully realized because of workplace demands, rather than masculine capacities to care. Interestingly, strands of discourse which emphasize natural capacities and biology - and which consequently have been much more associated with women as maternal subjects - are also woven through some of the men's accounts of transition.

\section{The Findings}

\section{Anticipating Fatherhood: Intentions and Imaginings}

The data collected in the antenatal interviews largely centred on the men imagining what fathering might be like and their intentions to 'be there' for their child(ren $)^{3}$ in ways they envisage will be qualitatively different to their own fathers. All the men produce culturally recognizable accounts which resonate with ideals of the good, involved father. These include intentions to be involved in hands-on and emotional aspects of caring for their new babies, sharing (sometimes) equally all facets of caring except where breastfeeding is planned. The men all talk about 'sharing care', 'caring', 'supporting', 'hoping to reduce work hours' and striking 'a decent balance' between caring and paid work. Men can occupy a novel space at this time ('I mean it's such a new world for me' Stephen, aged 29 years), in which societal assumptions of them possessing any pre-existing, essentialist instincts are largely absent. Consequently, the 'good' father-to-be is expected to avail himself of relevant information and attend birth preparation classes in order to demonstrate a commitment to being involved (Draper, 2002). The participants engage in these activities to a greater or lesser extent, usually orchestrated through their partner or wife. Reassurance is drawn from a belief that the mother of their child will instinctively know how to care for the baby once born, but anticipation of their own natural instincts - 'a fantastic bond' - emerging at the birth is also evident across some of the antenatal narratives. Interestingly, here the men invoke recognizable elements of discourses of nature and biological predisposition more usually associated with maternal bodies. Mike, 
who is 32 years old and employed in car sales, draws upon these as he alludes to his novice status in this antenatal phase, 'I don't know, I think I am only going to find out when it (the birth) happens and hopefully all the instincts, urges and so on kick in'.

All the men planned to take either statutory paternity leave of two weeks and/or saved annual holiday. Yet, more fundamental change of work patterns, which might enable the 'equal' or similar sharing that is envisaged, is not planned. From the outset, a false correlation is made which involves imagining that a physically small baby will make similarly small demands, which will only take up a small part of a 24-hour day. Imagining fathering involvement in this way makes it appear possible to equally share caring alongside other work commitments. Like all the fathers in the study, Sean, who is 33 years old, envisages being significantly involved in 'everything really' related to caring for the baby:

Initially the only thing that I think that I probably can't do is breastfeed [but] I don't see myself as not doing anything and in real terms Ella wanted to express (breast milk) anyway, so at some point I'll be able to feed ... But I don't see that there's going to be anything particularly that I won't do. Obviously Ella hopefully will be having nine months (maternity leave), so there will be far more that she'll be doing anyway, just because of time. [But] changing nappies and bathing, I'll try and have a go and get involved and do these things. (emphasis added)

Mike too talks of wanting to 'be a part of it as much as I can' and expects to 'wash it, bath it, change its nappy, feed it, wind it, burp it [and] whatever else kind of comes'. But like other fathers his involvement will occur around his job:

I just want to be a part of it as much as I can, as I say I only work 10 minutes away so it's an ideal situation if something should happen, work is quite flexible in that you know I can go home and build up flexi time and those kind of things so I expect to be rolling my sleeves up.

Nick, aged 33 years, also anticipates being significantly involved in caring for his child. He thinks men's involvement has 'changed hugely' with men now expected to be 'a primary carer rather than a breadwinner'. In the following extract Nick, who works in education, draws upon ideas of caring masculinities and uses language more readily associated with mothers to narrate his intentions: at some level these imply doing gender differently:

I've enjoyed looking after her (wife) and I think there's something about preparing for that primary care role ... I think there's something there about preparing myself for that primary care, that actually it's going to be up to me to prepare a bottle or a meal or a feed or whatever for our child.

However, Nick is not actually planning to take on the 'primary role' as in primary responsibility for the baby once it arrives as the term might imply, but rather primary responsibility is related to undertaking particular tasks, which correspond to those used to describe caring involvement by the other men. Ben, who is 32 years old and an artist, like Sean in an earlier extract, points to breastfeeding as one reason why caring for the baby cannot initially be completely equal, but he too talks of 'sharing' the responsibility of care and 'doing his bit': 
Well obviously it is not equal because at first Hannah is going to have to take responsibility for feeding ... [but] there is a sort of sense of shared, a very shared or a quality of kind of share in that responsibility so I will expect to be up in the night as well and just being there for them both and hopefully doing my bit, doing whatever I can ... I will have to be glad to do whatever needs doing.

What soon becomes clear from the men's antenatal accounts is how differently responsibilities of caring for a child are constructed and understood in relation to fathers and mothers, even though all imply at some level an intention to disrupt traditional patterns of caring. Hands-on caring is always described through supportive, and so secondary, task-based acts ('doing my bit'). The men can only imagine and articulate their caring involvement in this way because their wife or partner is already implicitly positioned (by them and in normative ideals of 'good' mothering and parenting) as having primary responsibility. This leaves space for Dylan, a 33-year-old agricultural worker, to envisage fathering in the following way:

But right from the start I would like to negotiate work so that I have, you know, sort of a day off work a week to be a father and to do child care and to be involved and I would really like to be able to maintain that throughout my working life if possible.

It is almost unthinkable that a woman could articulate her anticipated mothering in this partial and episodic way (Miller, 2005, 2007). But masculine identities and associated practices of agency are not subsumed within paternal identities as men anticipate doing fathering, as is the case for women becoming mothers. It remains acceptable for men to talk of 'fitting fathering in' and for work to remain dominant even where 'priorities' are said to be shifting. But, consequently, men can feel marginalized if they want to take on the primary caring role as a full-time father (Doucet, 2006).

Across the antenatal interviews the men position themselves as wanting to be involved fathers and doing things differently; for example, being 'more involved in doing tasks that would have been associated with a female role' (Mike). Although the participants engage a language more associated with maternal subjectivities - 'instincts', 'primary role', 'bonding' - and acknowledge a changing cultural backdrop, deeply embedded ways of doing gender and performing masculinities remain powerful in how caring and child rearing is, or can be, contemplated and so articulated. The dilemma in attempting to do gender differently in a sphere infused with 'pseudoscientific directives' and essentialist claims is to first overcome the legacy of these constructs and their continued impact on the binary categories of motherhood and fatherhood (Duden, 1993: 4). These categorizations both invoke particular constructions of masculine subjectivities and enable corresponding practices of agency. Involved fatherhood then assumes more emotional and hands-on care but economic provision is also a necessary dimension of being a good father. As William, who is 36 years old and employed in defence, acknowledges:

What I'm trying to say is when I'm around the house I think I'll be quite sort of hands on but there'll be lots of time because of my job that I won't be around the house. I'll be making the money to kind of look after them. 
Hegemonic constructions of worker identity as a prized dimension of masculinities and achievement sit at odds with constructions of more involved, emotional fatherhood that the men have also envisaged and which apparently herald new possibilities. Indeed, Nick inadvertently alludes to these alternative possibilities when asked how he thinks he will be involved in caring for his child:

At this stage I want to say in everything. I want to take the baby [to] do the weekly shop, I want to be doing the bath and staying at home so that Shelley can go out and all that. I want everything to be divided down the middle. How much of that is a fantasy ... in six months' time I might be very grateful that I'm the one who is going out to work.

What becomes clear through the antenatal interviews is that the men are aware of, and invoke, strands of discourse of involved fatherhood but in a context which is framed by an anticipated return to paid work. The men are able to discursively frame their intentions across a wider repertoire of masculine storylines than those available to women anticipating motherhood.

\section{Early Fathering Experiences:The Early Postnatal Interviews}

The birth of their first child(ren) provides the men with a different perspective from which to narrate their experiences as intentions are supplanted by experiences. The men are all present at the hospital births ${ }^{4}$ and subsequently take between two and seven weeks' paternity and/or holiday leave. Across all the men's early fathering narratives, recognizable aspects of involved fatherhood are prominently drawn upon. Additionally, some of the new fathers talk of having an 'immediate bond' with their child and a 'father instinct' kicking in, as aspects of caring are felt to have come 'naturally'. Emerging paternal identities are made visible and narrated through particular practices which are cited by the men. These include involvement in various hands-on activities across these very early weeks. Essentialist language (bonding and instincts) more traditionally assumed of mothers is also discursively invoked by the fathers, signalling a sense of more caring masculinities and the discursive resources (more emotional language) through which to narrate their feelings. There is a real sense of sharing and learning together through these early days and weeks following the birth and glimpses of the men engaged in caring relationships, which imply that traditional gendered patterns are being undone. Apart from breastfeeding, most of the men describe sharing 'evenly' - which does not necessarily mean equally - in caring for the baby. Chris, a 28-year-old administrator, is surprised by how 'kind of instinctive' he has found it:

I thought also I wouldn't settle into it as quickly as I have ... because I see babies as so delicate I thought I wouldn't necessarily know what to do with it. But it's kind of instinctive ... Yeah I think we take it pretty evenly, I mean until Susan starts expressing (milk) then I can't do the feeding but I do everything else.

But economic necessity coupled with very different lengths of paternity and maternity leave in the UK means that the men's resumption of paid work lurks ominously - and 
inevitably - over this period. All the men either say, or imply, that the very early weeks together at home have been important in helping them to become 'far more involved' with their new baby. For example, Ben describes these early weeks as having been a 'special time', but:

... then you go back to work and it is like you kind of have to sort of not withdraw from it, but I needed to get more sleep so Hannah dealt with the night a bit more and then whole days and then suddenly you become a bit more secondary [now] Hannah is kind of doing most of the care ... Then when you go back [to work] suddenly the routine is continually changing so just when you think you have got it he is changing because he is growing so quickly but I don't think I quite know all of the issues now ... and quite quickly you can feel out of it.

Ben, like the other fathers, moves from a very intense period of shared involvement and establishing a caring relationship with the new baby, to quite quickly being back in the familiar world of paid work.

As the men resume their place in the public sphere and so spend less time enmeshed in the detail of their baby's (changing) needs, they can soon feel and become out of touch with 'all of the issues' as 'every time you think you're in a rhythm, the baby then changes' (Richard, a 39-year-old teacher). Importantly, becoming proficient at recognizing and meeting a growing baby's needs is a continually changing enterprise and so the men can feel they never (quite) become 'expert' and/or primary in this relationship. Aspects of involvement are now much more mediated through their wife or partner who remains at home (on statutory maternity leave) as the primary carer and who, as Richard observes, are 'immersed in the minutiae' of everyday caring. A consequence of this is that the mothers become more practised at recognizing and responding to their baby's needs. This in turn can be interpreted as evidence of 'natural' maternal instincts and very soon the glimpses of engaged, involved masculine practices of caring, which signalled undoing gender, become a dim memory. Competing paternal and workplace demands lead the men to revise their earlier intentions.

Different constructions of maternity and paternity leave in the UK, shaped through policy and discourse, alongside the hard and exhausting work in the early weeks of new parenting, do not provide ideal conditions in which to try to disrupt or transgress normative parenting patterns: at times the path of least resistance may be to fall back upon these. By the time of the early postnatal interviews (between six and 12 weeks) most of the men have spent more time back at work than at home. Across the unfolding narratives, elements of the breadwinner discourse are more evident as they describe their inability to do caring in any way that approximates to 'sharing evenly', as envisaged earlier. The men's narratives across the early postnatal period conclude with greater emphasis placed upon rationalizing their involvement in relation to economic provision and protection ('I've got to make sure there is food in the cupboard' and 'the reason you work changes ... in some ways work becomes more important'). As Joe, a 28-year-old computer programmer, says 'I'd like to think I'd want to look after her all the time, but going to work is quite nice, you get that break and, like I say, it's great for me'. But even though antenatal intentions do not map out in the sustained ways anticipated in the early weeks, the men still participate in emotionally attuned, hands-on caring in the spaces around paid work in ways that, at times, undo aspects of traditionally gendered caring. 


\section{Returning to a New Normal: Later Fathering Episodes}

The later postnatal interviews were carried out with the participants at between nine and 12 months and a further nine interviews were carried out at two years. The data collected across these interviews show that men have continued to be more involved in practical caring tasks than they recall their own fathers to have been. Some describe being more involved now that breastfeeding has mostly ceased and they can participate in feeding their older and more responsive baby. Some of the fathers now take on regular solo caring for their baby during evenings and weekends as wives and partners return to or take on part-time, paid work. This requires debriefing and 'routines' are described by all the men as an essential aspect of being able to manage pockets of childcare. Two of the fathers have concentrated their regular working hours into a shorter working week in order to accommodate more childcare. Work outside the home remains a dominant theme, but one father, Nick, says he has tried to think differently about the hours spent at home and work: 'There are forty hours of the week that I'm not here but there's however many hours that I am here and I'm trying to work more on that.'

By the time of these later interviews, masculinist practices of gender and paternal subjectivities together with discursive and practical 'choices' have become clearer. The mismatch between earlier antenatal intentions and how fathering has become practised on a daily basis is now apparent. Lack of time as a consequence of full-time work is clearly one factor, but there are other factors too. In the following extracts, Gus, a 28-year-old cook, and Richard reflect on the dimensions of their involvement at home and, in doing so, crucially illuminate a key variable in how gender is done - having choices. This is illustrated in the following extract as Gus talks about food preparation for his baby, which is something he says he should 'probably do', but never does:

Because one of the roles that Anna, one of the things that she does regularly is she gets his food ready for the next day. So (she) goes into the freezer, gets out a cube of whatever, puts it all into pots ... it's something she does every night. I should probably do it but I never do ... I think you know it's always said to me that blokes can switch off a little bit more. I'm sure scientists have done tests on our brains which says you know blokes can just sort of switch off, whereas women when they go to bed, a million things can be going around their head.

Richard also alludes to what he sees as the practical differences between masculine and feminine caring behaviours:

I'm doing plenty of childcare [but] Ros is taking responsibility for her [the baby's] future orientation of where we will be going next ... It's not that I couldn't do that but I'm not doing that ... men can't do it because men can't do practical things, actually it is easy to feed the baby but knowing what to feed her tomorrow is difficult.

In these extracts the two fathers rationalize differences they have encountered in relation to caring practices, knowledge and responsibilities when compared to their wives or partners: and there were many examples across the data. Gus invokes a discourse of science ('tests') to support his actions, whilst implicitly alluding to his own agency. Differences in how gendered behaviours are conceptualized and how consequent choices 
operate and can be articulated and indeed accomplished - 'It's not that I couldn't do that, but I'm not doing that' - are crystallized here.

Although the men are more involved in childcare activities than in their own fathers' generation, they are also able to exercise agency as fathers in ways not so readily available to women as mothers (especially in relation to the work place) and so have greater choices available to them (Miller, 2005, 2011). They also very quickly realize that paid work is more highly valued than the largely invisible ('feminine') work of child care at home ('it's more difficult to feel that this is something that is really important and good', Graham, a civil servant aged 32 years) and they have a wider range of discourses through which to narrate and situate their choices around work and home life. Research over many years has shown that 'the importance of being a breadwinner to men's identities remains strong' (Thébaud, 2010: 334) and the men confirm this in these later interviews. Capturing these interconnected themes, Dylan confides:

... all sorts of issues have come up that I never dreamed, you know, the male pride thing, that is very important now, more so than ever ... that my existence is justified ... that I sort of still feel the need to prove myself perhaps in my job more than anything else and perhaps it's not valid or recognized to prove yourself as a father.

Dylan's concern about 'the male pride thing' is culturally recognizable within hegemonic masculinities discourse and associated gendered behaviours. In the earlier study on motherhood, women also recognized and missed the 'status thing' of paid work and many eventually returned to work, combining paid work and child care in a range of ways (Miller, 2005). But unlike the men, the new mothers could not invoke so acceptably 'the female pride thing' and/or discourse of the breadwinner. They carefully constructed narratives to demonstrate an accomplishment of gender that showed they were not bad or negligent mothers just because they also worked.

\section{Falling Back into Gender?}

The aim at the outset of this article was to more precisely explore and theorize dimensions of doing - and undoing - gender. The unfolding narratives have shown that whilst there has been a move away from 'a single model of unified masculinities' and evidence of more emotional engagement in fathering practices, elements of hegemonic masculinity and associated subjectivities, agency and power endure (Connell, 1995; Morgan, 2002: 280). The legacy of patriarchal and structural arrangements, men's power and 'choices' cannot be erased from contemporary debates or experiences even if there is a desire to do so. The men's intentions of doing gender differently, and so caring in ways that are described as 'shared', 'even' and sometimes 'equal', is only partially realized. During the early weeks following the birth there are clear examples of 'undoing gender' according to Deutsch's definition - 'social interactions that reduce gender difference' (2007: 122). But the practices of undoing gender that are glimpsed do not occur in a vacuum. Both individual ('male pride thing') and structural ('then you go back to work') elements of patriarchal histories and habits, which have denoted accomplished performances of hegemonic masculinities, provide a potent backdrop against which 
new fathering is experienced, and which is different in significant ways to normative assumptions and associated practices around motherhood (Miller, 2011). The physical ('I never expected a child to be so much, to need so much attention or work or time', Dylan) and emotional ('it is more emotionally draining than I thought', Nick) aspects of becoming a father for the first time do not produce the circumstances in which more than partial and/or temporary disruptions of normative gendered behaviours are achieved. In spite of the best of intentions, returning to performances of selves which are recognizable, familiar and so also gendered can be a path of least resistance in this new world of parenthood. For example, Stephen, who is a 29-year-old IT worker, talks of having 'got into a really nice relaxed routine' in which his wife 'looks after the baby all day' so that he 'can bring in [economic] support for the family' and also meet the payments on their ' $100 \%$ mortgage'. Nevertheless, around this apparently traditionally configured arrangement, Stephen, like the other fathers, is also engaged in hands-on caring for his young son which is 'quite a lot of hard work ... not something ... you can teach to somebody [but] something they'd have to pick up' and concludes by affirming that he has 'got quite a strong bond with [his] son'. Interestingly, Stephen here positions himself as both breadwinner and father who has learnt the skills of caring and has a 'strong bond' with his child: a description of fathering which demonstrates doing gender in traditional ways and at times simultaneously doing - and discursively narrating gender differently.

What the data show then is new fathers undoing and doing gender in partial and sometimes temporary ways that are also contingent and at times accomplished, simultaneously. Optimistically, caring involvement and practices which can reduce gender differences are both possible and evident in the data. But parenting contexts are complex because of how gender has been done and the persistence of patriarchal legacies and associated practices of agency. These continue to enable men to construct and justify caring responsibilities and obligations alongside work choices through the wider array of discourses available to them as men, fathers and workers. It 'is no mean feat' then as Björnberg and Kollind have observed to overcome 'fixed gender norms' or the 'informal mechanisms that lead to different conditions or possibilities' for both men and women (2005: 131). The data show that opportunities to transgress normative ways of doing caring can also be refused or avoided ('I should probably do it but I never do'), and/or explained through apparent incompetence ('they're with each other all the time, Sophie's much better at picking up on cues and knowing when baby is needing food or tired'), and so normative patterns of gendered behaviours continue.

\section{Conclusion}

This article has explored the experiences of a predominately middle-class group of men as they become fathers for the first time. It has done so as policy on parental leave has become a key focus in political and popular debate. The longitudinal data show that whilst sharing, equality and sameness in caring for the unborn child is anticipated and narrated, there is a naivety about how this will be practically managed and sustained alongside full-time paid work. In part, the introduction of two weeks' paid paternity leave in the UK enables these men to envisage significant sharing in hands-on caring. 
However, without any previous knowledge of the often hard, time-consuming and relational work of caring, their hopes and intentions turn out to have been overstated. Following the birth the men are indeed more actively and emotionally involved in caring for their child than they recall their own fathers to have been. But a return to paid work reveals the temporary nature of any intentions - or possibilities - to significantly disrupt normative gender behaviours. The fathers' caring practices are not forgotten, however, but rather are developed more slowly as they are squeezed into evenings and weekends: and their wives or partners quite quickly become more 'expert' through practice. Importantly, the relational dimensions of caring and being continually attuned to a baby/ child's changing needs are revealed across the data - and yet are currently absent from policy debates. Even though paternity leave is embraced, more durable elements of hegemonic masculinities in relation to (the value of) paid work and associated choices are eventually drawn upon as intentions and responsibilities are discursively reframed. Although the structural context in the UK in which fathering is accomplished is undergoing some change for some fathers, the pace and extent of change is slow and does not reflect the significant changes which have occurred in women's lives as mothers and workers. Whilst taking turns in aspects of caring, and glimpses of doing gender differently, are discernible across the data, for the most part it remains the mother who is left holding the baby.

\section{Acknowledgements}

Thanks are given to all the men who shared with me their unfolding experiences of transition to fatherhood.

\section{Notes}

1 This consultation process has resulted in changes to maternity/paternity leave being introduced (April 2011). These changes allow fathers to share paid maternity leave up to a total of six months if certain criteria are met. http:/www.direct.gov.uk/en/Parents/ Moneyandworkentitlements/WorkAndFamilies/Paternityrightsintheworkplace/DG_190788)

2 It proved difficult to arrange the first postnatal interviews as the men were back at work. These interviews took place over a longer period (between six and 12 weeks) than those in the earlier motherhood study (6-8 weeks).

3 Two of the participants knew from antenatal ultrasound scans that their partners had conceived twins.

4 One of the 17 births was a planned home delivery.

\section{References}

Björnberg U and Kollind A (2005) Individualism and Families. Abingdon: Routledge.

Bray I, Gunnell D and Davey Smith D (2006) Advanced paternal age: how old is too old? Journal of Epidemiological Community Health 60(10): 851-53.

Coltrane S (1996) Family Man. New York: Oxford University Press.

Connell RW (1995) Masculinities. Cambridge: Polity.

Dermott E (2008) Intimate Fatherhood. London: Routledge.

Deutsch FM (2007) Undoing gender. Gender \& Society 21(1): 106-26.

Doucet A (2006) Do Men Mother? Toronto: University of Toronto Press. 
Draper J (2002) 'It was a real good show': the ultrasound scan, fathers and the power of visual knowledge. Sociology of Health and Illness 24(6): 771-59.

Duden B (1993) Disembodying Women: Perspectives on Pregnancy and the Unborn. Cambridge, MA: Harvard University Press.

Duncan S, Edwards R and Alexander C (2010) Teenage Parenthood: What's the Problem? London: Tufnell Press.

Featherstone B (2009) Contemporary Fathering. Bristol: Policy Press.

Fox B (2009) When Couples Become Parents. The Creation of Gender in the Transition to Parenthood. Toronto: Toronto University Press.

Gatrell C (2007) Whose child is it anyway? The negotiation of paternal entitlements within marriage. The Sociological Review 55(2): 352-72.

Gillies V (2009) Understandings and experiences of involved fathering in the United Kingdom: exploring classed dimensions. The Annals of the American Academy of Political and Social Science 624(1): 49-60.

Hearn J and Pringle K (2006) European Perspectives on Men and Masculinities: National and Transnational Approaches. Basingstoke: Palgrave Macmillan.

Henwood K and Proctor J (2003) The 'good father': reading men's accounts of paternal involvement during the transition to first-time fatherhood. British Journal of Social Psychology 42: $337-55$.

Hobson B and Morgan DHJ (2002) Introduction. In: Hobson B (ed.) Making Men into Fathers: Men, Masculinities and the Social Politics of Fatherhood. Cambridge: Cambridge University Press.

Johansson T and Klinth R (2007) Caring fathers. The ideology of gender and equality and masculine positions. Men and Masculinities 11(1): 42-62.

Jurik NC and Siemsen C (2009) 'Doing gender' as canon or agenda: a symposium on West and Zimmerman. Gender \& Society 23(1): 72-5.

Knijn T and Selten P (2002) Transformations of fatherhoods: The Netherlands. In:Hobson B (ed.) Making Men into Fathers: Men, Masculinities and the Social Politics of Fatherhood. Cambridge: Cambridge University Press.

Lamb ME, Pleck JH, Charnov EL and Levine JA (1987) A biosocial perspective on paternal involvement. In: Lancaster J, Altmann J, Rossi A and Sherrod L (eds) Parenting across the Lifespan: Biosocial Dimensions. New York: Aldine de Gruyter.

Lupton D and Barclay L (1997). Constructing Fatherhood: Discourses and Experiences. London: SAGE.

McNay L (2000) Gender and Agency. Cambridge: Polity.

Marsiglio W and Pleck J (2005) Fatherhood and masculinities. In: Kimmel S, Hearn J and Connell RW (eds) Handbook of Studies on Men and Masculinities. London: Sage.

Miller T (2005) Making Sense of Motherhood: A Narrative Approach. Cambridge: Cambridge University Press.

Miller T (2007) 'Is this what motherhood is all about?' Weaving experiences and discourse through transition to first-time motherhood. Gender \& Society 21(3): 337-58.

Miller T (2011) Making Sense of Fatherhood: Gender, Caring and Work. Cambridge: Cambridge University Press.

Morgan DHJ (2002) Epilogue. In: Hobson B (ed.) Making Men into Fathers: Men, Masculinities and the Social Politics of Fatherhood. Cambridge: Cambridge University Press.

O'Brien M (2005) Shared Caring: Bringing Fathers into the Frame. Working Paper 18. Norwich: University of East Anglia.

Risman B (2009) From doing to undoing: gender as we know it. Gender \& Society 23: 81-4. 
Ruddick S (1997) The idea of fatherhood. In: Nelson HL(ed.) Feminism and Families. London: Routledge.

Shirani F and Henwood K (2011) Continuity and change in a qualitative longitudinal study of fatherhood: relevance without responsibility. International Journal of Social Research Methodology 14(1): 17-29.

Thébaud S (2010) Masculinity, bargaining, and breadwinning: understanding men's housework in the cultural context of paid work. Gender \& Society 24(3): 330-54.

Townsend NW (2002) The Package Deal: Marriage, Work and Fatherhood in Men's Lives. Philadelphia, PA: Temple University Press.

Vuori J (2007) Men's choices and masculine duties. Fathers in expert discussions. Men and Masculinities 12(1): 45-72.

Wall G and Arnold S (2007) How involved is involved fathering? An exploration of the contemporary culture of fatherhood. Gender \& Society 21(4): 508-26.

West C and Zimmerman D (1987) Doing gender. Gender \& Society 1(2): 125-51.

Williams S (2008) What is fatherhood? Searching for the reflexive father. Sociology 42(3): 487-502.

Tina Miller is a Professor in Sociology at Oxford Brookes University. Her research and teaching interests include motherhood and fatherhood transitions, constructions of gender and identities, reproductive health, feminist theory, narratives, qualitative research methods and ethics and she has researched and published in these areas. Tina has been engaged as an expert adviser by the World Health Organization, presented her work at UNICEF headquarters and participated in various TV and radio programmes in relation to her research and publications on motherhood and fatherhood. She is currently working with colleagues at Milan University on a comparative study of men, work and fatherhood and with colleagues at WHO on a project on maternal health.

Date submitted December 2010

Date accepted March 2011 